\title{
Memorabilia cinematográfica: as materialidades do cinema como reflexo de cinefilias
}

\section{Film memorabilia: the materialities of cinema as a reflection of cinephilias}

Joana Isabel Fernandes Duarte ${ }^{1}$; $1_{\text {E-mail: }}$ joanaisabelfduarte@gmail.com Faculdade de Letras da Universidade do Porto
Resumo: O cinema, uma das expressões artísticas mais populares e influentes do século XX, era, durante esses anos, objeto de fascinação. A tentativa de preservar a experiência cinematográfica e de a estender para lá do ecrã foi desde cedo um ensejo de muitos cinéfilos, e o star system tirou partido dessa necessidade mítica e afetiva para criar produtos materiais que recordassem ou substituíssem o que se vira na sala de cinema.

O presente artigo reflete sobre memorabilia cinematográfica como revistas, programas de sessões, fotografias (distribuídas nos mais variados formatos, desde cartonados, cromos, postais), publicidade fílmica (cartazes, cartonados, standees) e outros objetos perecíveis a que as imagens do cinema foram associadas para instigar o consumo e coleção por parte dos cinéfilos. Pretende-se, ainda, chamar à atenção para o cariz patrimonial destes objetos. Outrossim, propuseram-se categorias para organizar esta memorabilia e tentou-se compreender de que forma se espelham nestes itens duas cinefilias distintas: uma popular e outra mais intelectualizada.

Palavras Chave: memorabilia cinematográfica, revistas de cinema, cinefilia, fotografia de estrelas, publicidade fílmica

Abstract: Cinema, one of the most popular and influential artistic expressions of the 20th century, was an object of fascination. The attempt to preserve the cinematographic experience and to extend it beyond the screen was, since early times, a goal for many moviegoers, and the star system took advantage of this mythical and affective need to create products that recalled or replace what is seen in the movie theater.

The goal of this article is to understand cinematographic memorabilia such as magazines, movie programs, photographs (distributed in varied formats), film advertising (posters, lobby-cards, standees) and other perishable objects to which the images of movies were associated to instigate consumption and collection by the cinephiles. It is also our aim to draw attention to the patrimonial aspects of these objects. Moreover, we propose categories to organize this memorabilia and we tried to understand two distinct cinephilias that are reflected in these objects: the one that is "popular" and the one that is "intellectualized".

Keywords: film memorabilia, film magazines, cinephilia, movie star photography, film publicity 


\section{pontéditora}

\section{Considerações prévias}

O presente artigo pretende versar sobre as diferentes materialidades do cinema, analisando e contextualizando os tipos de objetos pertencentes a este espectro da memorabilia cinematográfica e propor a organização destas peças em categorias. Bem assim, é propósito deste trabalho demonstrar como alguns destes itens refletem dois tipos de cinefilia distintos: um de feição mais popular e outro de cariz mais erudito.

Sob o ponto de vista metodológico, para responder a tal intento, tirou-se partido da análise da quase totalidade de revistas especializadas em cinema publicadas entre 1912 a 2000 em Portugal, bem como de uma revisão bibliográfica geral do tema e menção a algumas coleções museológicas que preservam e exibem estes objetos. A temática da memorabilia cinematográfica é relativamente inexplorada em Portugal, tendo em conta a escassez de trabalhos académicos que reflitam sobre esta matéria num espectro alargado. Por outro lado, existem investigações sobre nichos específicos que compõem os objetos cinematográficas colecionáveis, como cartazes (vd., a título exemplificativo, Trancoso, 2018; Ramos, 2014; Samara e Baptista, 2010), habitualmente os produtos mais sonantes quando se pensa nas materialidades do cinema extrafílmicas ${ }^{\mathrm{i}}$, e, mais recentemente, as revistas de cinema ( $v d$. Duarte, 2018). Não obstante, é de destacar, no âmbito português, monografias divulgativas como o catálogo da exposição Cinema em Portugal: os primeiros anos, que se realizou em 2010 no Museu da Ciência da Universidade de Lisboa, que apresentou vários componentes da memorabilia cinematográfica pertencentes à coleção da Cinemateca Portuguesa / Museu do Cinema. Efetivamente, a Cinemateca Portuguesa tem levado a cabo, nos últimos anos, uma divulgação do seu acervo (fílmico e não fílmico) através de pequenas exposições temporárias. Destaque-se igualmente o trabalho de alguns cineclubes, como o Cineclube do Porto, na valorização de espécimes como programas de sessões de elevado interesse gráfico (CLUBE PORTUGUÊS DE CINEMATOGRAFIA, 2016). Em Espanha, onde há uma maior profusão de objetos vinculados à memória do cinema, são numerosos os estudos e catálogos sobre coleções cinematográficas para lá das películas ${ }^{\mathrm{ii}}$. 
O cinema, como arte da imagem em movimento, teve a sua imaginária associada a uma certa fugacidade e impossibilidade de cristalização, quer pela rápida sucessão de fotogramas, quer, sobretudo, pela vinculação da assistência às salas de exibição. Desde cedo, contudo, que se tentou materializar a experiência cinematográfica - vista no ecrã - em objetos móveis, passíveis de serem guardados. A indústria cinematográfica tira proveito, sobretudo a partir dos anos 20, desse desejo de um objeto que congele e avive a memória da experiência cinematográfica, ao mesmo tempo que o alimenta: é o tempo do star system, que vingará até ao final dos anos 50 .

Os objetos que se adquirem e se querem guardar são, nesse sentido e na conceção de Baudrillard,

«(...) fora da prática que deles temos, (...) algo diverso, profundamente relacionado com o indivíduo, não unicamente um corpo material que resiste, mas uma cerca mental onde reino, algo de que sou o sentido, uma propriedade, uma paixão» (Baudrillard, 1993: 94).

A decisão de guardar objetos que trespassem o seu tempo, a sua geração, é, ao mesmo tempo, um reflexo de um momento particular da humanidade: porque, afinal, «colecionamos a nós mesmos» (Baudrillard, 1993: 99) a partir de objetos que nos relembram dos nossos sonhos, medos, desejos e conquistas ${ }^{\text {iii }}$. Estes interesses adquirem, muitas das vezes - como neste caso, se atendermos aos contornos quase religiosos que este hábito obteve na primeira metade do século XX - um cariz coletivo.

Graças aos "colecionadores"iv de objetos relacionados com o cinema, preservava-se, assim, uma grande parcela da memória de imagens da nossa civilização - sejam elas ficcionadas ou reais. Reside nessa materialização e "objetificação" do cinema e das suas imagens (a priori, não fixáveis pela sua natureza mutável) parte da essência da memorabilia cinematográfica, composta por elementos de natureza variada e distintos entre si, que, no nosso entender, se poderá dividir em quatro categorias principais:

1. OBJETOS DE COLEÇÃO. Objetos “cinéfilos" feitos, desde logo, para guardar e/ou colecionar. Inserem-se nesta categoria as revistas, os postais, os cartazes, as fotografias - que 
eram difundidos desde a década de 10 - e o merchandising, que se torna mais popular a partir da segunda metade do século XX. Recorde-se, nesse sentido, os bonecos originais do Mickey da Walt Disney e as estratégias de marketing surgidas nos anos 60 associadas aos Universal Classical Monsters da Universal Studios (que fizera, anos antes, películas como FRANKENSTEIN [James Whale, 1931] e DRACULA / DRÁCULA [Tod Browning, 1931], com os clássicos atores de terror Boris Karloff e Bela Lugosi) - e sobretudo as figuras de ação e de outros itens associados a grandes sucessos de bilheteiras (blockbusters), como STAR WARS / GUERRA DAS ESTRELAS (Georges Lucas et al, 1977-2018) nas décadas de 70 e 80 .

2. OBJETOS DE CONSUMO. Objetos de consumo a que eram associados os rostos das "estrelas" de cinema, de forma a impulsionar a compra por parte do cinéfilo. Tratam-se de objetos de utilidade concreta, comestíveis ou de aplicabilidade efémera; isto é, objetos perecíveis, a menos que conservados com dedicado cuidado. Inserem-se nestas categorias embrulhos de caramelos, chocolates, caixas de fósforos e embalagens de tabaco.

3. SOUVENIRS. Objetos materiais, como adereços e elementos de cenários, utilizados nos filmes pelos realizadores e atores, e que se tornaram «recuerdos» (Cervera 1999: 38). Atenda-se, por exemplo, aos sapatos que Judy Garland usa no filme THE WIZARD OF OZ / O FEITICEIRO DE OZ (Victor Fleming, 1939). Os cartonados (lobby-cards) e cartazes, bem como outro género de impressos de publicidade aos filmes, também se poderão enquadrar nesta categoria, enquanto objetos produzidos e distribuídos pela indústria cinematográfica.

4. OBJETOS HISTÓRICOS. Objetos que espelham e registam a própria evolução da história do cinema sob o ponto de vista da tecnologia. Inserem-se nesta categoria os objetos da arqueologia da imagem em movimento: desde o pré-cinema - como lanternas mágicas - às câmaras de projeção e de filmagem, aparelhos de som, material de laboratório, etc. Conhecem-se colecionadores, como é o caso de Wilfred Ernest Lytton Day (1873-1936), que desde os primeiros anos da invenção do cinema já guardavam e vendiam este género de equipamentos (Nogueira, 2004: 47). A maioria dos espólios das cinematecas consiste em objetos desta génese, embora não exclusivamente. 
Tais categorias não devem ser lidas de forma estanque, até porque muitos itens podem fazer parte de uma e outra tipologia: o cartaz pode ser um objeto histórico ou de souvenir. Dentro destas quatro categorias, chamamos à atenção para o facto de alguns destes elementos serem colecionados não apenas pelo amor aos filmes, mas também, muito particularmente, pelo modo como as vedetas, com a sua popularidade que extrapolava o âmbito cinematográfico, influenciavam e impulsionavam os fãs a incorporar os seus comportamentos, hábitos e vestimentas (categoria 2). A preservação desses objetos dever-se-á mais do que amor ao cinema, ao amor e o culto às "estrelas". Estes objetos cumprem a dupla função de para além de uma utilidade prática concreta, serem também possuídos.

A fascinação exercida pelo cinema, manifestada nos objetos nomeados (alguns deles, quais vanitas), constitui hoje um património da humanidade onde «ha podido ir quedando expresado el comportamiento de un siglo, sus formas de vida, sus costumbres, su grandeza o mezquinidad» (Patino, 1999:15), as suas paixões. A cinefilia, como nos demonstrou Edgar Morin (Morin, 1980) e Basilio Martín Patino, chegou a ser «la más esplendorosa religión de nuestro tiempo» e os objetos desse amor ao cinema são «las huellas físicas de su arte, o de su secta, en la que, en vez de arqueologia habría que hablar de relíquias» (Patino, 1999:15).

Face a um fenómeno de tal dimensão e complexidade, consideramos que o termo «cinefilia», na primeira metade do século, dificilmente se poderia ter manifestado uniformemente. De facto, alguns autores fazem a distinção entre cinemaníaco (aquele que revela um amor ao cinema sem distinções, filtros, critérios, consumindo tudo de forma igual), o cinéfilo (normalmente com uma imbricação entre o cinema e outros produtos culturais) e o cinefágico (que sente uma atração e reivindica a periferia da cultura instituída, privilegiando os géneros populares e com defeitos, a série B, etc.) (Ferrando, 2012: 74). Para efeitos deste artigo, ao invés da designação singular cinefilia, adotamos a expressão cinefilias, fazendo a distinção entre três principais: uma de cariz popular, que chama às massas que buscam entretinimento e evasão - pode inserir-se, nesta categoria, o fãa, aquele que tem uma paixão cumulativa, com «neuroses de colecionista e fetichista» (Aumont apud Ferrando, 2012: 74), embora nem toda a cinefilia popular se manifesta desta forma-; uma outra de características, dir-se-iam, "intelectuais", por parte daqueles que refletem sobre o cinema e visam a sua legitimação como arte; e, por fim, uma cinefilia algo híbrida, a meio caminho entres estes extremos. Esta organização corresponde, ressalvamos, a uma simplificação - a título 
exemplificativo, são muitos os géneros "populares" que apelam, igualmente, à fração "intelectual": recorde-se a simpatia dos Cahiers du Cinéma (Paris, 1951-) face ao cinema americano em detrimento da "qualidade do cinema francês" então vigente. Em todas estas cinefilias se sente a necessidade de colecionar objetos relativos às suas paixões, com mais ou menos intensidade e variando no conteúdo. A cinefilia popular é mais permeável à coleção de retrato das "estrelas", enquanto a mais "erudita" privilegiará, por norma, objetos relacionados com a memória e arqueologia do cinema.

Importa sublinhar que embora a UNESCO tenha considerado, na Recomendação sobre a salvaguarda e conservação das imagens em movimento (UNESCO, 1980), as imagens em movimento como «uma expressão da personalidade cultura dos povos e que, por causa do seu valor educativo, cultural, científico e artístico, formam parte integrante do património cultural de uma nação», a verdade é que a memorabilia cinematográfica não-fílmica (isto é, a que extravasa a projeção da imagem em movimento) carece, habitualmente, de valorização enquanto bem patrimonial. Uma das mais importantes instituições de valorização de arquivos fílmicos - a Fédération internationale des archives du film (FIAF) - também tem como um enfoque, desde a sua criação em 1938, a conservação de filmes. Estas posições são compreensíveis se tivermos em consideração a quantidade de filmes que se perderam, na primeira metade do século passado, pela falta de preservação e de bom acondicionamento das películas (objetos frágeis e altamente inflamáveis), antes do estabelecimento das cinematecas enquanto lugares de conservação e divulgação do património audiovisual. Todavia, os testemunhos extrafílmicos reportam-se, também eles, a um legado da paixão do cinema e, muito particularmente, de memória e de identidade - aspetos essenciais para falarmos em noções de património (Almeida, 1993: 408) - de uma coletividade num determinado momento. Para além de exercerem uma função de arquivo, constituindo um património histórico e documental, estes objetos também podem adquirir valores estéticos pela importância que assume a fotografia e as artes gráficas [Figs. 1-5]. Além do mais, periódicos como revistas e programas de sessões integram igualmente a noção de património bibliográfico, por refletir noções de memória, história e estética, segundo as aceções da Lei 107/2001 (Art. 85). São, em suma, testemunhos de «civilização ou de cultura portadores de interesse cultural relevante», ou seja, um conjunto de bens culturais (Art. 2) que, na definição de Leniaud, «uma geração sente que deve transmitir às seguintes porque pensa que esses bens são um talismã que permite à sociedade compreender o tempo nas três 
dimensões» (Leniaud apud Almeida,1993: 409). Abordaremos, neste artigo, alguns desses talismãs, como as revistas, os programas de cinema, as fotografias colecionáveis, os pontos, e alguma publicidade fílmica como cartonados e cartazes, espelho desse tempo em que o cinema - que é feito da mesma matéria daquilo que estão feitos os sonhos (Cabrera Infante, 2001: 100) - movia milhares de pessoas que acudiam às salas de espetáculo e cineclubes.

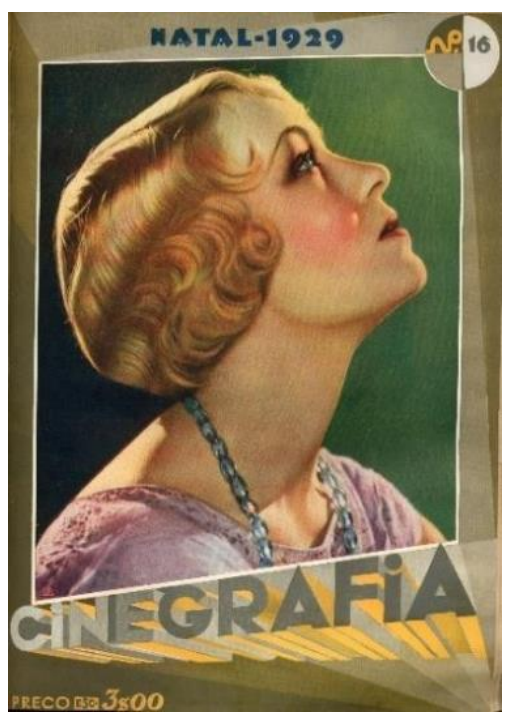

Figura 1 - Retrato de Mary Pickford. Fotografia com pintada e retocada. Fonte: Cinegrafia (N. $\left.{ }^{\circ} 16\right), 1929$

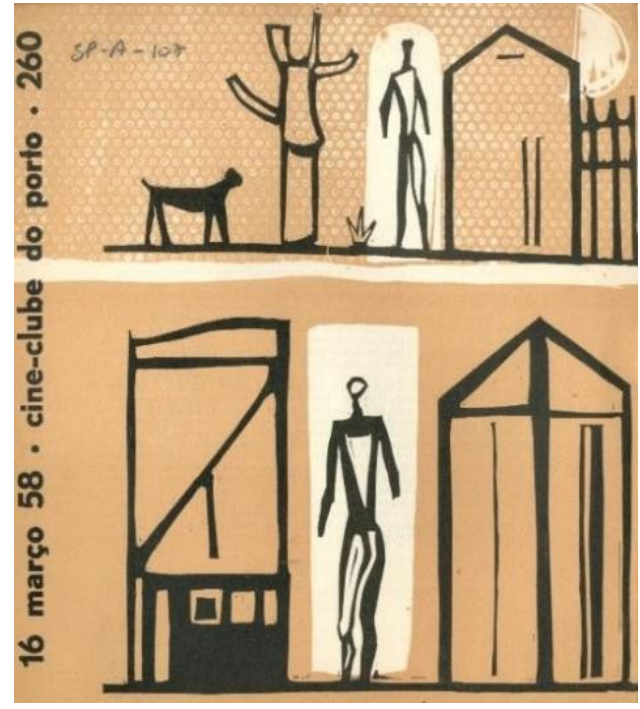

Figura 2 - Programa de sessão com capa atribuída a Ângelo de Sousa. Fonte: Cine-club do Porto (N. $\left.{ }^{\circ} 260\right), 1958$

\section{As revistas e os programas de cinema}

As revistas de cinema constituem um dos mais valiosos objetos cinematográficos nãofílmicos, pela inestimável informação de ordem noticiosa nelas contida, assim como pelas críticas aos filmes e artigos de opinião, que nos demonstram bem as formas de entender o cinema ao longo do tempo. Todavia, estas fontes não devem ser descuradas, igualmente, do ponto de vista visual. Nelas ensaiaram-se e incorporam-se novos modelos de reprodução imagética $^{v}$, de desenho, de caricatura, e, nos anos 50, de banda-desenhada (Duarte, 2018). Da mesma forma, o papel desta imprensa no alimentar de uma certa cinefilia - a que quer ver as fotografias das "estrelas" - reporta-se indesmentível e foi um instrumento poderosíssimo do star system (Duarte, 2018: 88).

As fotografias dos filmes, enviadas pelas distribuidoras ou migradas através de outras redações de revistas, nacionais e estrangeiras, possibilitavam não só guardar as fotografias dos filmes já estreados ou na iminência de estrear, mas também aqueles filmes que não se viam (fosse pela censura ou por escolhas de distribuição), mas com os quais se sonhava. 
Estas imagens, aliadas à crítica cinematográfica (também ela alimentada de entrevistas, artigos e críticas de outra imprensa estrangeira), davam a conhecer ao público cinéfilo novas teorizações e movimentos do cinema. Nesse sentido, compreende-se que na imprensa especializada se multipliquem rubricas como «Filmes que não vimos» ou «Filmes que vamos ver», que antecipam essa impossibilidade de os conhecer e de pensar sobre eles.

É nas revistas de cinema que mais se sente a existência de cinefilias distintas, que se extremam particularmente a partir dos anos 50. Enquanto nas décadas de 20 e 30 a crítica e a teoria cinematográfica coexistia (e bem) com as fotografias de vedetas e o teor "cor-de-rosa" que se dedicava à vida pessoal das "estrelas", a partir dos anos 50, passa a existir uma completa cisão relativamente à essa imprensa "híbrida": por um lado, começa a existir uma imprensa que ser quer séria - e que, por este mesmo motivo, irá rejeitar todo o cariz ilustrativo dos magazines, particularmente o das "estrelas" - por outro, existe uma outra imprensa que vai continuar a publicar fotografias dos filmes, das estrelas no seu quotidiano. Este fenómeno - o da procura de um cinema novo, a rejeição de stars - deve ser confrontado com novas formas de pensar o cinema, como o Neorrealismo e a Nouvelle vague, onde os protagonistas eram, muitas das vezes, atores não-profissionais. Nesse sentido, o papel da estrela vê-se diminuído, embora em Hollywood prossiga a aplicação dos preceitos do star system e o culto às vedetas. Estas duas vertentes - a de uma imprensa mais preocupada com o bom cinema, e a de uma preocupada com as notícias do "estrelato" - demonstram duas formas de entender o cinema e da sua relação afetiva com ele. Nesse sentido, as revistas espelham uma cinefilia que ora é híbrida, ora intelectual, ora popular.

Os programas de cinema, que se inscrevem no âmbito de publicações periódicas especializadas, possuíam, até ao final dos anos 30, um tratamento estético e informativo que não se confinava à mera divulgação do filme (sinopse, ficha técnica, pequena crítica): nela publicavam-se fotografias dos atores, dos filmes, e curiosidades sobre os mesmos. Exemplo desse preciosismo ao nível dos programas está patente no programa Trindade, do Cinema Trindade, no Porto.

Verifica-se que, sob o ponto de vista gráfico, nem todos os números eram uniformizados e muitos revelavam engenhosas e apelativas

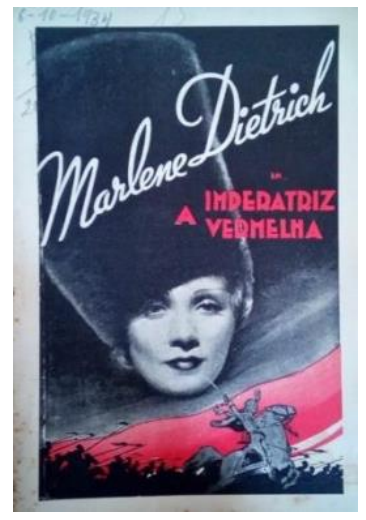

Figura 3 - Programa de sessão do Cinema Trindade, dedicado ao filme SCARLET EMPRESS / A IMPERATRIZ VERMELHA (Josef von Sternberg, 1934). Em grande destaque figura o nome e rosto da vedeta. Fonte: Programa Trindade, 1934. 
composições [Fig. 3]. Além do mais, muitas destas capas eram assinadas (no caso dos programas do Trindade da década de 30, por João Alberto e João Heitor). Por sua vez, nos anos 50 assiste-se a uma progressiva uniformização dos programas de sessão: tornam-se menos personalizados e criativos, dominados pelas empresas de publicidade como a Belarte, obedecendo a esquema pré-determinado e com menor interesse estético.

\section{Fotografias das vedetas}

A difusão de fotografias das vedetas é, desde os primórdios do star-system, fundamental para a indústria publicitária sediada em Hollywood e para que um filme vendesse bem. Os fotógrafos de cena (still photographers) correspondiam a uma profissão específica que tratava de fotografar quer aspetos de cenas concretas dos filmes (como se fossem fotogramas), quer os seus protagonistas, habitualmente em poses glamorosas, para fins publicitários [Fig. 5-6]. As fotografias deste género eram distribuídas por todo o mundo, fossem em revistas, cartazes, ou sob a forma de postais e cartões-de-visita, em variadíssimos formatos. São várias as menções a empresas especializadas na reprodução destas fotografias $^{\text {vi }}$, e não raras vezes as revistas oferecem, dentro da sua publicação, imagens descartáveis das "estrelas", como em nas revistas Portugal Cine (Lisboa, 1923) e Colipo Cine (Leiria, 1930-1931). Ademais, considere-se que nos anos 30 e 40 é frequente que a capa e contracapa, nos magazines, focalizem no rosto da star [Fig. 4-5].

A coleção de fotografias era de tal importância, que ainda hoje são numerosos álbuns de fotografias e de cromos guardados pelas cinematecas (Museu da Ciência da Universidade de Lisboa, 2010: 86). Os pedidos insistentes para a publicação de fotografias das estrelas nas revistas, bem como a referência aos clubs de fãs com o principal objetivo de «decorar as paredes com fotografias de Lilian Harvey» (Pereira, 1932: 3) e de vedetas afins, tornam visíveis como a existência de fãs e a sua organização em fan-clubs é uma forma de cinefilia popular e de um colecionismo popular por excelência. Em alguns casos mais drásticos do culto às vedetas (recordar os suicídios na sequência da morte de Rodolfo Valentino), o objeto idolatrado é, desta feita, o humano (Nogueira, 2004: 22). Na impossibilidade de o obter, o colecionador busca tudo o que gravite em torno do objeto idolatrado - as fotografias, que funcionam como substituto da presença real -, tudo aquilo que segrede «uma parcela de intimidade da estrela» (Morin, 1980: 68-69), e tudo o que faça com que o espectador se 
assemelhe ao objeto amado. Estas relações psicoafectivas de projeção e identificação, muito estudadas por Morin, evidenciam que a "estrela" corresponde a uma necessidade afetiva e mítica do homem. O star system, ao impulsionar a circulação destas imagens, possibilita as suas formas, osseus suportes e os «afrodisíacos» (Morin, 1980:79) dessa necessidade.

Alguns dos fotógrafos de vedetas mais importantes eram Ruth Harriet Louise (uma das poucas mulheres dedicadas à profissão de still photograph, e que logrou alcançar admirável sucesso) e Clarence Sinclair Bull, que trabalharam sobretudo nos anos 20 e 30 e eternizaram o rosto de atrizes como Louise Brooks, Greta Garbo [Fig. 6] ou Jean Harlow. Ainda que a maioria das imagens das "estrelas" sejam de identificação autoral difícil, pois raramente são circuladas com legendas nas revistas e postais, verifica-se que alguns estúdios, como a Warner Bros ou a MGM, utilizavam um sistema de código de letras e números para a identificação dos seus filmes, habitualmente no canto inferior das imagens (Nogueira, 2004: 167) [Fig. 6]. Estas "chaves", devidamente investigadas nas imagens da imprensa de cinema portuguesa, poderão ser objeto de um estudo para a atribuição de autorias.

As imagens fixas (fotografias) das estrelas, objeto de adoração por uns, objetos de memória por outros, eram, nas palavras da atriz Louise Brooks, o que os espetadores mais recordam: «when I think of Garbo I do not see her moving (...) I see her staring mysterioulsy into the camera (...) she is a still picture» (Kobal, 1988: 122).

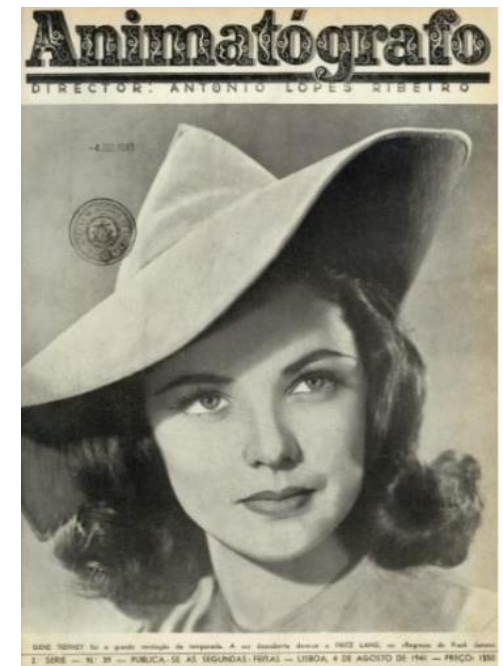

Figura 4 - Retrato fotográfico de Gene Tierney na capa de
Animatógrafo. Fonte: Animatógrafo (2 ${ }^{\text {a }}$ Série, N. $\left.{ }^{\circ} 39\right), 1941$

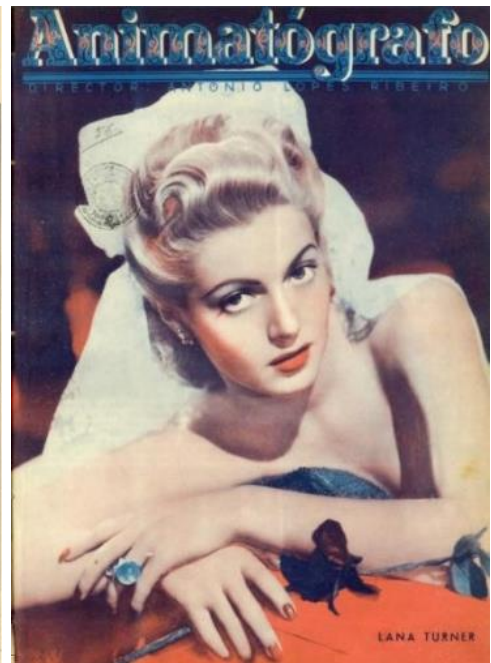

Figura 5 - Retrato fotográfico de Figura 6 - Retrato fotográfico de Animatógrafo. Fonte: Animatógrafo Louise. 1928. Fonte: Paddle 8 (2 $2^{\mathrm{a}}$ Série, N. $\left.{ }^{\circ} 56\right), 1941$

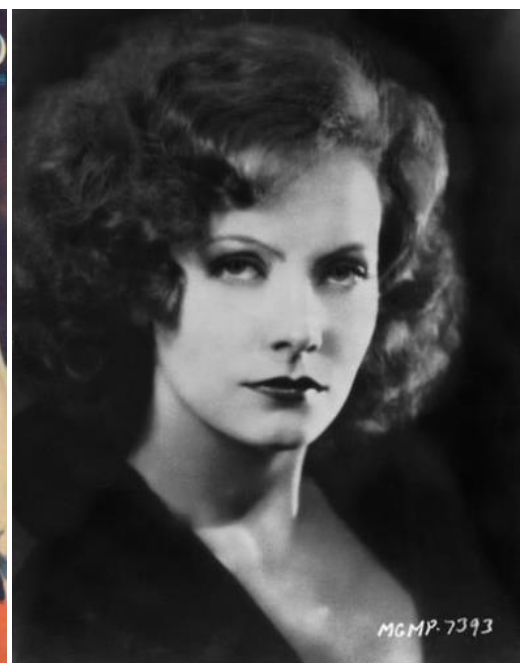

Auctions 


\section{Fotografias dos filmes e pontos}

As fotografias dos filmes ganham espaço quer num universo pessoal (o das revistas), quer no espaço público (nas salas de espetáculo, nas ruas). Na imprensa periódica, para além da multiplicação de fotogramas ou fotografias ser mais variada e profusa, num mesmo número, era também colecionável, passível de ser guardada e consultada variadas vezes. Como referimos, as fotografias dos filmes, fossem de cena (stills) ou fotogramas, possibilitavam uma antevisão da película e, muitas das vezes, eram o único substituto visual destas. Habitualmente, captam imagens memoráveis no espectador, como a cena de Marilyn Monroe em cima da ventilação do metro com o seu vestido branco a esvoaçar e a descobrir-lhe as pernas em THE SEVEN YEAR ITCH / O PECADO MORA AO LADO (Billy Wilder, 1955). Verificamos que, tendencialmente, as revistas de cinema de pendor "intelectual" (isto é, que elevam o cinema a arte e refletem e escrevem sobre ele, e não sobre os seus protagonistas) dos anos 50, quando são ilustradas (habitualmente parcamente), possuem quase sempre fotografias de cena/fotogramas, e não de estrelas ${ }^{\text {vii }}$. Assim, a difusão de certas imagens em determinados meios é também demonstrativa da (co)existência de cinefilias distintas nessa década.

Os pontos correspondem a um dos objetos da memorabilia cinematográfica "involuntários" mais curiosos. Consistiam em fotogramas que paravam às mãos dos cinéfilos graças a algumas imperfeições mecânicas dos projetores que destruíam largos metros de película, que depois eram cortados pelos projecionistas e deixados na cabine ou no lixo ao fim de cada sessão. Facilmente se compreende como estes objetos se tornam num nicho de coleção e, até mesmo, de pequeno comércio entre cinéfilos (Museu da Ciência da Universidade de Lisboa, 2010: 87). Em Portugal, como demonstrado pelas exposições do acervo da Cinemateca, tal fenómeno terá sido comum nos primeiros anos do cinema. Situação semelhante é descrita no filme JACQUOT DE NANTES (Agnès Varda, 1991), um hino à cinefilia de cariz biográfico, a propósito da visa do cineasta Jacques Demy, e que mostra bem as circunstâncias de roubo e comércio dos pontos entre cinéfilos.

\section{Formas de publicitar os filmes: cartonados, cartazes e telões}

Os cartonados (do inglês lobby-cards) - que terão surgido ainda na década de 10 destinavam-se a publicitação do filme no átrio, nas bilheteiras e foyers das salas de cinema. Os cartonados eram impressos num papel mais grosso do que o cartaz e constituíam, 
habitualmente, um conjunto de seis a dez fotografias sobre um mesmo filme, afixados lado a lado, de forma a suscitar interesse na fita e a revelar algumas das cenas (Museu da Ciência da Universidade de Lisboa, 2010: 74). Correspondiam a fotografias de cena e/ou a fotogramas dos filmes, preferencialmente destacando as "estrelas". Nos cartonados, a imagem é o meio de comunicação privilegiado. Por sua vez, os title card tinham, a par da imagem de cenas dos filmes, o título da película em grande destaque (Warren, 1194: 10-13).

À semelhança dos cartonados - que se encontravam no interior dos edifícios de cinema também os cartazes, os telões e os standees correspondem a uma prática eficaz de publicitar os filmes, quer no interior (cartazes, standees), quer no exterior (cartazes, standees e telões). Estes objetos de publicidade fílmica pontuavam, de forma mais ou menos elaborada, as salas de espetáculo do país.

Os cartazes são os objetos de memorabilia talvez mais populares e conhecidos, e desde cedo objeto de coleção. Embora inicialmente fossem de cariz tipográfico e textual, a inclusão da fotografia no cartaz foi progressivamente tomando lugar na década de 10 do século XX. Condensando através de uma forte imagética a identidade visual do filme, de forma a captar a atenção do transeunte nas ruas ou nos átrios de cinema, a venda de cartazes - muito popular - chegou, por um breve período, a ser proibida, no início dos anos 40 nos Estados Unidos (Nogueira, 2004: 155). Os materiais impressos, quando fornecidos pela indústria, eram propriedade do estúdio e deveriam ser devolvidos após o fim da exibição. Todavia, logo se percebeu a potencialidade desses itens para a venda, pois apelavam a muito público (Ibidem: 156).

Se a história do cartaz de cinema e da sua coleção ${ }^{\text {viii }}$ é relativamente glosada, encarada e valorizada, em muitos casos, enquanto peças artísticas (vide a prática cartazista soviética dos irmãos Stenberg e a americana de Saul Bass), o mesmo não se poderá dizer de elementos de cariz efémero como são os "telões". Os telões consistiam em telas pintadas ${ }^{\mathrm{ix}}$, podendo ser reutilizáveis, que faziam parte de decorações efémeras das fachadas de cinema. Conhecemos estes itens de publicidade fílmica quase exclusivamente por registos fotográficos e textuais. Por se tratarem trabalhos quase sempre não assinados e a existência estar comprometida pela efemeridade inerente a estas peças, raramente é possível a identificação de autorias. A partir dos anos 50, a tendência foi para que as grandes produtoras e distribuidoras dos filmes 
forneçam já todo o material publicitário (cartazes, cartonados, postais, etc.) (Acciaiouli, 2013: 150), pelo que outras iniciativas começaram a rarear ${ }^{\mathrm{x}}$. De facto, Hollywood dá continuidade à narrativa cinematográfica ao criar o Sistema de Identidade Visual, que unifica os elementos base de referência e identificação, tais como logótipos, tipos de letra, marca, cores, que são aplicados a determinados itens (Nogueira, 2004: 105).

A par dos telões, existiam outras iniciativas que dotavam o edifício de uma certa tridimensionalidade, seja através de letterings ou de standees (imagens recortadas, normalmente em tamanho real, alusivas aos protagonistas dos filmes) [Fig. 7-8]. O interesse na coleção deste tipo de objeto, a partir da fotografia (pois as dimensões, por norma, não permitiriam o seu armazenamento) reside na originalidade e raridade dos objetos.

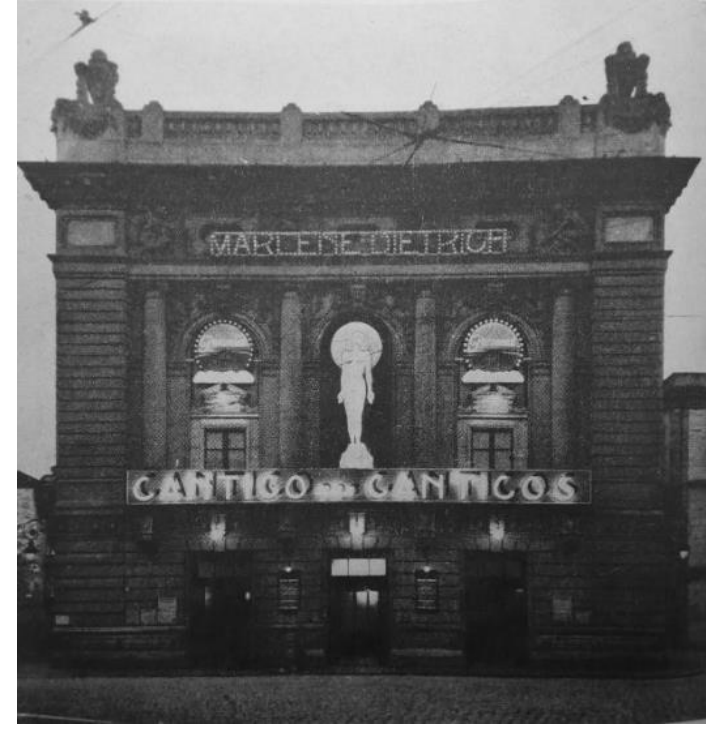

Figura 7 - Publicidade ao filme SONG OF SONGS / CÂNTICO DOS CÂNTICOS (Rouben Mamoulian, 1933). Fonte: Cinéfilo. A. 7, N. 303 (junho 1934), p. 14

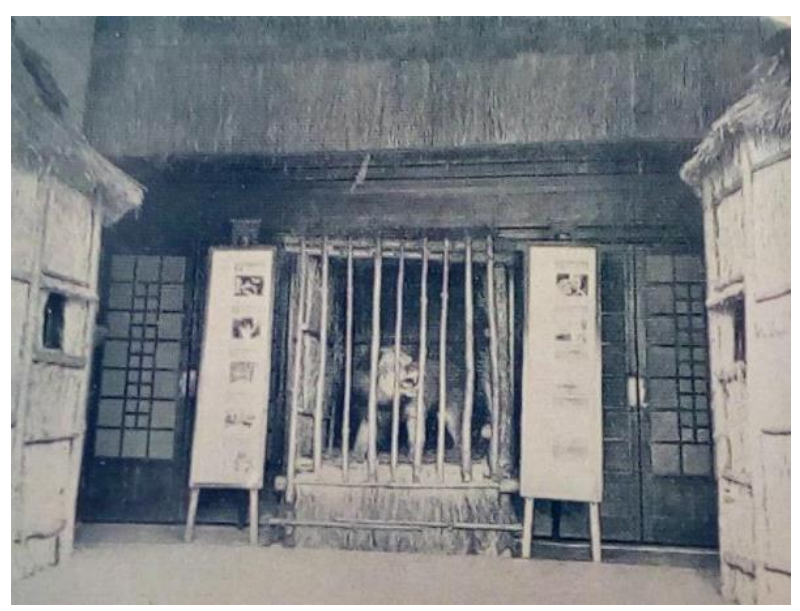

Figura 8 - Átrio do cinema Águia D’Ouro, no Porto, com standees e outros materiais publicitários que recriam o ambiente do filme NAGANA (Ernst L. Frank, 1933). Fonte: Cinéfilo (1935)

\section{Outra memorabilia cinematográfica: objetos comercializáveis}

Ademais de selos, postais, caixas de fósforos, entre outros objetos utilitários e comercializáveis, está documentada a existência de associação das imagens de vedetas a objetos perecíveis, como chocolates, caramelos, cigarros, entre outros. Terá sido prática corrente nos anos 20 e 30 do século XX um pouco por todo o mundo. A existência de vestígios desta ordem é relativamente rara, não tendo conhecimento se existirão nos acervos e espólios dos museus dedicados ao cinema em Portugal. O catálogo Cinema português primeiros anos refere, contudo, essa prática. Em Espanha, estão registadas em Valladolid, 
empresas como Santo Antonio e Quirino San Pedro que vendiam chocolates e cafés que distribuíam séries de cromos com fotografias e, no reverso, com textos sobre as intimidades dos artistas do cinema, alusivos à sua vida privada (Hermosa e Jiménez, 1997: 39). Também em Barcelona haveriam fábricas de chocolate, como a Piera \& Brugueras que disponibilizavam coleções de retratos de cinema (Idem: 50).

Estas estratégias de marketing, que de resto ainda hoje são utilizadas, com devidos ajustes e adaptações à realidade e necessidades contemporâneas, evidenciam o papel da "estrela" em vender outras itens para lá dos filmes em que participa. O star system tirou proveito deste panorama para enriquecer e popularizar ainda mais a indústria do cinema.

\section{Considerações finais}

O presente artigo pretendeu colmatar uma lacuna sentida no âmbito da memorabilia cinematográfica e sua categorização, bem como apresentar leituras que, em retrospetiva, se podem fazer dos públicos que compravam e colecionavam estes elementos - que, como vimos, não são categorizáveis de forma uniforme.

Evidenciou-se que as indústrias cinematográficas, bem como algumas marcas e empresas locais, tiram partido do encanto que as "estrelas" de cinema exercem nos seus fãs para potenciar o consumo de determinados produtos. Nesse sentido, compreende-se que as "estrelas" e os "ases" do cinema desta época sejam consideradas autênticos «heróis de consumo» (Geada, 1987: 119), que norteiam o que (e como) vestir, usar, comportar, comer. Se é certo que estas características são associadas, de modo geral, a uma cinefilia de feições populares e massivas, não é menos verdade que a cinefilia intelectual acusa igualmente um certo fetichismo cinematográfico: recorde-se a importância que as fotografias de cena exercem na imprensa especializada, ou como a geração da nouvelle vague se refere ao espólio da Cinemateca de Henri Langlois. Efetivamente, o conhecimento da memória do cinema através de objetos materiais muito terá impressionado esta geração de cineastas: como diz Jean-Luc Godard «Nuestros padres, nuestros professores, todos de ambientes intelectuales, nos hablaban de Rembrandt, de Mozart (...) un día, de pronto, tuve la oportunidade de conocer outro museo distinto, extraordinário...» (Godard apud Patino, 1999: 16), referindo-se ao «dragão que vigia os nossos sonhos» (Jean Cocteau apud Patino, 1999: 16). Tais odes à Cinemateca demonstram bem a carga patrimonial que, nos anos 60 , se sentia 
relativamente aos objetos preservados nas Cinematecas, habitualmente de cariz histórico.

Algumas destas peças, que visavam comunicar e prolongar a experiência do cinema nos espectadores, converteram-se em objetos de museu e de coleção por representarem estas mitologias cinéfilas, sobretudo quando o filme em questão desaparece da atualidade (Frutos Esteban, 1999: 127). Revela-se, assim, essencial uma maior valorização de outros elementos materiais da cultura cinematográfica que não os já muito glosados cartazes e objetos históricos (câmaras e outras máquinas de cariz tecnológico). O ato de guardar e organizar fotografias, revistas, postais, programas de sessões de cinema, e outra memorabilia são, também, documentos que fazem parte do património do século $\mathrm{XX}$, no sentido em que registam a história do cinema, dos hábitos societários associados a ele, das salas de espetáculo que pontuavam as cidades das capitais e das províncias, mas, também, de um sentimento e de uma forma de estar perante aquele que foi um maiores fenómenos culturais e populares do século passado. Poucos objetos cristalizam tantos universos imaginários como os associados ao cinema, que no século XX, ao contrário de outras artes, se abria a todo o género de classes e meios sociais.

Sublinhe-se que, relativamente ao século passado, as estratégias de merchandising e de promoção de filmes através de objetos comercializáveis não abrandaram. Tome-se o exemplo de produção de $t$-shirts, canecas, ímanes, bonecos e materiais de papelaria associado a sagas populares do cinema, como o já referido STAR WARS ou HARRY POTTER.

Tendo em consideração que este trabalho foi realizado a partir, sobretudo, da análise das revistas, de uma revisão bibliográfica e da reflexão e organização de elementos a partir de catálogos de exposições, é igualmente certo considerar que o estudo apresenta determinadas limitações: para uma reflexão completa e holística deste património seria indispensável a análise, a partir de determinada coleção, de alguns dos objetos a que aqui nos referimos (caixas de fósforos, cartonados) e de que só tivemos o conhecimento por intermédio bibliográfico e fotográfico. Estas limitações conferem ao trabalho um caráter generalista, que gostaríamos de ver aprofundado e aplicados ao espólio cinematográfico em Portugal. 


\section{Notas de rodapé}

${ }^{\text {I }}$ Embora extrafílmico remeta para variadas aceções, usamo-lo aqui no sentido restrito de tudo o que ultrapassa o filme (enquanto produto audiovisual e meio) e as máquinas de filmar e de projeção.

II Ver Frutos Esteban, 2000 e Filmoteca Española, 1999.

III Se é certo que existem sonhos, medos, desejos e conquistas intemporais, isto é, transversais à história da humanidade, também é verdade que, por vezes, existem tendências e pequenas cambiantes. O cinema é também reflexo de sentimentos e preocupações em particulares momentos da história.

IV Uma coleção significa escolher e reunir (Baudrillard, 1993: 11) e difere de acumular. Sublinhe-se que a acumulação de todos objetos de um qualquer fã não constitui, em si, um bem patrimonial. É necessário haver critérios e fios condutores significados que não se restrinja, exclusivamente, a um «discurso de si próprio» (Ibidem: 113). Nas matérias de património, a seleção é essencial. Ao longo deste artigo utilizaremos "coleção" e “colecionador", entre aspas, quando o sentido não deverá remeter para uma Coleção museológica organizada, mas sim num sentido mais abrangente, referente à seleção e recolha de objetos.

${ }^{\mathrm{v}}$ As revistas de cinema aproveitaram, desde o início, inovações técnicas como a impressão em rotativa e a rotogravura, que possibilitam um maior espectro da linguagem das imagens através, por exemplo, da fotomontagem.

VI Em 1924, a «Papelaria da Moda», na Rua do Ouro em Lisboa, anuncia a venda de postais e fotografias das principais estrelas e «azes» do cinema, em «mil variedades» e três formatos diferentes $(4,5 \times 0,6 \mathrm{~cm} ; 9 \times 14 \mathrm{~cm}$; $18 \times 24 \mathrm{~cm}$ ), que variavam entre os 50 centavos, os 2,50 escudos e 6 escudos (S.A., 1924: [s.p]).

\footnotetext{
VII Ver o estudado quantitativo levado a cabo por Duarte 2018: Vol. II, 48-59.

VIII Existem, inclusive, monografias que "guiam" os colecionadores para os preços a pagar por cartazes autênticos (Warren, 1994).
}

IX No caso das fachadas do Cinema Condes e do Éden, nos anos 30, os telões eram pintados por um artista chamado Adriano Rodrigues (Roiz). O pintor assistia a uma projeção privada do filme e a partir da memória dessas imagens produzia a sua composição, embora também pudesse inspirar-se a partir de outro material publicitário e documental sobre o filme (Cinemateca Portuguesa 2016, [1]). O S. João Cine e Águia D’Ouro, no Porto, teriam pela mesma época oficinas de pintura «instaladas na retaguarda do palco» com «pessoal especializado [que] trabalha permanentemente na execução de vistosas e variadas tabuletas que, todas as semanas, nas varandas do São João Cine e Águia D’Ouro anunciam os filmes de exibição» (S.A., 1938: 3).

${ }^{\mathrm{x}}$ Excetuam-se, neste contexto, por exemplo, os cartazes e programas de sessões que se faziam no âmbito dos cineclubes. 


\section{Referências bibliográficas}

Acciaiuoli, Margarida. 2013. Os cinemas de Lisboa: um fenómeno urbano do século XX.

Lisboa: Editorial Bizâncio.

Almeida, Carlos Alberto Ferreira de. 1993. Património: Riegl e hoje. Revista da Faculdade de Letras História - II série, vol. 10, p. 407-416

Baudrillard, Jean. 1993. O sistema dos objetos. São Paulo: Perspectiva.

Cabrera Infante, Guillermo. 2001. Cine o sardina. Madrid: Punto de Lectura.

Cervera, Elena. 1999. La exposición Soñar al cine. Filmoteca Española (1999). Soñar el cine. [s. 1.]: Ministerio de educación y cultura.

Cinemateca Portuguesa. 2016. Roiz, / Os frescos do cinema. [Folheto da exposição "Roiz/Os frescos de cinema patentes na Cinemateca Portuguesa/Museu do Cinema em abril/maio de 2016]. Lisboa.

Clube Português de Cinematografia/Cineclube do Porto; Cooperativa Árvore (coord.). [2016] Cinema gráfico: programas do Cineclube do Porto. 71 anos Cineclube do Porto. Porto: Clube Português de Cinematografia; Cooperativa Árvore.

Duarte, Joana Isabel Fernandes. 2018. «Se não se podem ver filmes, leiam-se as revistas». Uma abordagem da imprensa cinematográfica em Portugal (1930-1960). Volume I e II. Relatório de estágio do Mestrado de História da Arte, Património e Cultura Visual, apresentado à Faculdade de Letras da Universidade do Porto. Porto: [edição de autor]. Disponível em linha < http://hdl.handle.net/10216/114328>

Ferrando, Jorge Nieto. 2012. Cine en papel. Cultura y crítica cinematográfica en España (1962-1982). Valencia: Ediciones de la Filmoteca.

Frutos Esteban, Francisco Javier. 1999. Fabricar sueños: arte e industria cinematográfica. in Filmoteca Española. 1999. Soñar el cine. [s. 1.]: Ministerio de educación y cultura. 
Frutos Esteban, Francisco Javier. 2000. Artilugios para fascinar: colección Basilio Martín Patino. [Salamanca]: Junta de Castilla y León. Consejería de Cultura y Turismo.

Geada, Eduardo (1987). O cinema espectáculo. Lisboa: Edições 70.

Hermosa, José Luis Castrillón; Jiménez, Ignacio Martín. 1997. El espectáculo cinematográfico en Valladolid (1920-1932). Valladolid: Junta de Castilla y León.

Kobal, John. 1998. The art of the great Hollywood portrait photographers. London: Pavilion Books.

Lei n. ${ }^{\circ}$ 107/2001. 2001. Lei de bases do património cultural Português. Diário da República

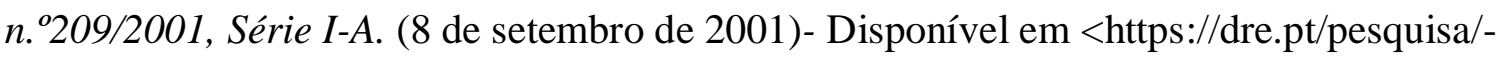
/search/629790/details/maximized>

Morin, Edgar. 1980. As estrelas. Lisboa: Livros Horizonte.

Museu da Ciência da Universidade de Lisboa. 2010. Cinema em Portugal: os primeiros anos. Lisboa: Museu de Ciência da Universidade de Lisboa / Imprensa Nacional Casa da Moeda.

Nogueira, Soraia Nunes. 2004. A imagem cinematográfica como objeto colecionável: o colecionador na era digital. Dissertação no âmbito do Mestrado de Artes Visuais apresentada à Escola de Belas Artes da Universidade de Minas Gerais. Minas Gerais: [Edição de autor]

Patino, Basilio Martín. 1999. Soñar el cine. in Filmoteca Española. 1999. Soñar el cine. [s. 1.]: Ministerio de educación y cultura.

Pereira, Alberto Armando. 1932, 5 de novembro. O Cantinho dum Cinéfilo. Cinema. Ano I, N. 33 , p. 3.

Ramos, Igor Alexandre Pereira. 2014. 100 anos de design no cartaz de cinema português: 
1912- 2012. Dissertação no âmbito do Mestrado em Design apresentado à Universidade de Aveiro. Aveiro: Universidade de Aveiro.

S.A. 1924, março. Papelaria da Moda. Cine, N. ${ }^{\circ} 10$.

S.A. 1938, dezembro. “São João Cine - Águia D’Ouro: duas casas de espectáculos ao serviço do público". S. João da Águia. N. 104

Samara, Maria Alice; Baptista, Tiago. 2010. Os cartazes na primeira república. Lisboa: Tinta da China.

Trancoso, Paulo. 2018. O cartaz de cinema em Portugal: uma exposição, uma viagem. [s.1.]: Academia Portuguesa de Cinema.

UNESCO. 1980. Recommendation for the Safeguarding and Preservation of Moving Images.

Belgrado: UNESCO. Disponível em < http://portal.unesco.org/en/ev.php$\underline{\text { URL_ID }=13139 \& U R L \_D O=D O \_T O P I C \& U R L \_S E C T I O N=201 . h t m l}>$

Warren, Jon R. 1994. Collecting Hollywood. The Movie poster price guide. Chattanooga: American Collecting Exchanges. 